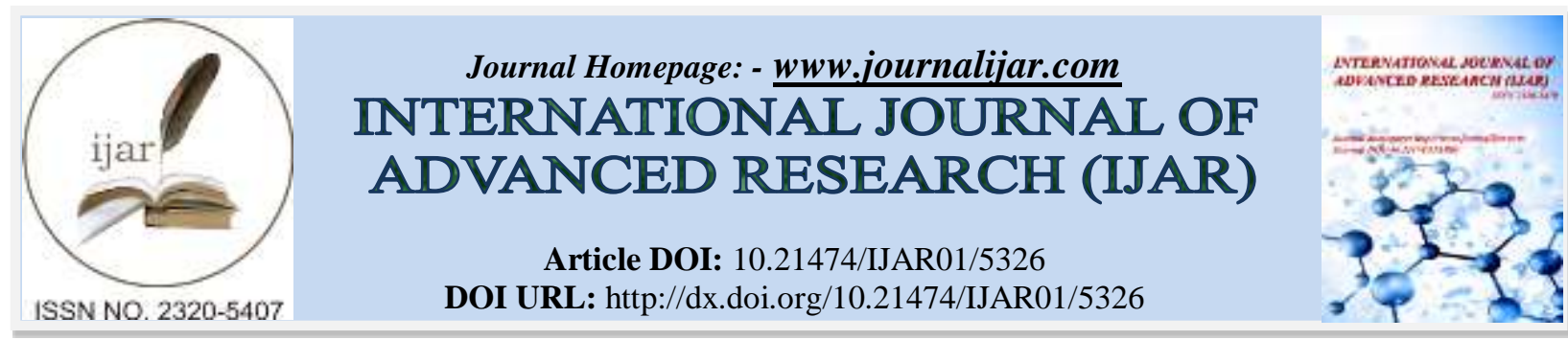

RESEARCH ARTICLE

\title{
ASSESSMENT OF FAMILY MEDICINE RESIDENTS' SATISFACTION REGARDING THE HALF DAY RELEASE COURSE OF FAMILY MEDICINE PROGRAM.
}

1. MBBS, Family Medicine Resident.

\section{Tamara Alsharif ${ }^{1}$ and Samera Hussein ${ }^{2}$.}

2. Consultant Family Medicine, Jeddah.

\section{Manuscript Info}

Manuscript History

Final Accepted: 06 August 2017

Published: September 2017

Key words:-

Family Medicine, Medical Education, Residency program, Half day release course.
Received: 04 July 2017

\begin{abstract}
Objectives: To assess FM resident's satisfaction and determinants of dissatisfaction regarding the HDRC of the JPFCM program in Makkah Al-Mukarramah Region.

Methodology: Following a cross-sectional design, this study included 147 FM residents in Makkah Al-Mukarramh Region. A validated questionnaire was designed by the researchers for data collection, which was sent by WhatsApp messages and emailed to all FM residents registered at Makkah Al-Mukarramah JPFCM Program.
\end{abstract}

Results: The highest residents' satisfaction was related to "environment and teaching methods", while the lowest was that for "presenter and presentation". Residents' satisfaction differed significantly according to their age groups and academic levels, being least among those aged $>30$ years, and those in R4. Satisfaction regarding "environment and teaching methods" differed significantly according to their city and participants' time. Satisfaction regarding "organization" differed significantly according to presenters and participants' time. Satisfaction regarding "overall satisfaction" items differed significantly according to presenters and participants' time, seniors and half day time having the higher dissatisfaction.

Conclusions: The highest residents' satisfaction regarding HDRC is related to "environment and teaching methods", while the highest dissatisfaction is related to "presenter and presentation" component. Highest dissatisfaction toward all components are among senior presenters, aged $>30$ years and those at R4. Residents have more dissatisfaction toward the half-day course than the full-day course.

Copy Right, IJAR, 2017,. All rights reserved.

\section{Introduction:-}

Family medicine as defined by the American Academy of Family Physicians (AAFP) is the medical specialty which provides continuing, comprehensive health care for the individual and family. It is a specialty integrates the biological, clinical and behavioral sciences. The scope of family medicine (FM) encompasses all ages, both sexes, each organ system, and every disease entity. ${ }^{1}$

In Saudi Arabia, the Family Medicine Board Program was established in 1994, under the umbrella of the Saudi Commission of health specialties. It is mainly composed of 4 levels of training starting by introductory course, 
family medicine module courses, Hospital rotations through different medical specialty, Research course, and half day release course. ${ }^{2}$

The half day release course (HDRC) is a session of four hours once weekly in the afternoon time for all family medicine residents for all levels. The primary objective of the HDRC is to acquire up to date knowledge and skills. $60-80 \%$ of sessions presented by the trainees. The HDRC schedule should contain different topics with different teaching methods such as journal clubs, consultation skills, update lectures on outbreaks, skills workshop, and presentation skills. Also, it should contain feedback sessions minimum twice per year and awards for those with perfect attendance and high marks ${ }^{2}$.

Recently, The National Guard residents were separated from the JPFCM and currently they have their own teaching sessions. They have full day release course instead of half day, and the sessions are presenting by the residents and consultants. In Al-Taif Joint program the residents in the level 4 have another HDRC only for them.

Since the HDRC is a crucial part of the JPFCM, assessment of FM residents' satisfaction toward the HDRC is quite important. Therefore, this study aimed to assess FM resident's satisfaction about the HDRC of the JPFCM in Makkah Al Mukaramah Region and to identify determinants of their dissatisfaction.

\section{Methodology:-}

This study was conducted during August and September 2016, following a cross-sectional design. The study population included all FM residents from level 1 (R1) to level 4 (R4) registered at the JPFCM in Makkah AlMukaramah Region (N=206). The JPFCM in Makkah Al-Mukarramah comprises Makkah Al-Mukaramah, Jeddah and Al-Taif cities. Only 147 FM residents responded, with a response rate of $71.4 \%$. Nine FM residents were affiliated to the Ministry of National Guard (outside the JPFCM), while 138 FM residents were affiliated to the JPFCM.

A specific online English-Language questionnaire was designed by the researchers for data collection. It has been validated by 3 Family and Community Medicine consultants. The questionnaire comprised demographic characteristics, general information about the HDRC, residents' satisfaction grade regarding four components, i.e., presenters and presentations ( 7 items), environment and teaching methods (6 items), organization ( 8 items), and the overall satisfaction (7 items).

Participants' responses for each satisfaction statement were assessed according to a 4-point Likert scale, where "4" indicated the highest, and "1" indicated the lowest agreement.. Therefore, the scores for each item within each component range from 1 to 4 . The total for each component was calculated by adding each resident's scores for its constituent items. Percentage scores were then calculated by dividing the resident's total score for each component by the number of its items and multiplying by 100 .

The researchers obtained all FM residents' email addresses and phone numbers from the JPFM in the study region. The questionnaires were sent to all residents via WhatsApp messages containing the questionnaire's link, at least twice. To improve response rate, the questionnaire's link was emailed to them.

The researcher started data collection after fulfillment of all the necessary official approvals from the JPFCM in Makkah Almukaramah Region. Each resident was informed that by filling the questionnaire he/she accepts to participate in this research. Confidentiality of the data was completely confirmed.

Data entry and analysis were done using the Statistical Package of Social Sciences (SPSS, version 21). Independent samples t-test and one-way ANOVA (F-test) were applied to test the significance of differences between mean percent scores of FM residents' satisfaction according to their characteristics. Statistical significance was considered when $\mathrm{p}$ values were less than 0.05 .

\section{Results:-}

Table (1) shows that most participants (71.4\%) were 26-30 years old. More than two thirds of residents (69.4\%) were females. More than one third of residents (38.8\%) were in Jeddah City, 28.6\% were in Makkah Cty, while $32.7 \%$ were in Al-Taif City. Most presenters were residents (97.3\%), mostly in a half day release course (93.9\%). 
More than one fourth of residents (27.9\%) were in R1, 25.2\% were equally in R2 and R3 while $21.8 \%$ were in R4. Presenters were mainly residents $(97.3 \%)$, mostly in a half day release course $(93.9 \%)$. Table (2) shows that the highest mean percent score was that for environment and teaching methods $(65.5 \pm 14.3 \%)$, while the lowest was that for presenter and presentation $(53.3 \pm 14.8 \%)$.

Table (3) shows that regarding the "presenters and presentation" component, "topic preparation" was the item that received the highest satisfaction level (Mean \pm SD: 2.74 \pm 0.78$)$, followed by "practical topic" (Mean \pm SD: 2.72 \pm 1$)$ and "lecture organization" (Mean \pm SD: 2.70 \pm 0.79 ). On the other hand, the highest residents' dissatisfaction (i.e., least satisfaction) was about "presenter enthusiasm" (Mean \pm SD: 2.46 \pm 0.7 ) and "presentation skills" Mean \pm SD: 2.48 $\pm 0.7)$. Regarding the "environment and teaching methods" component, "using of audiovisual aids" was the item that received highest satisfaction (Mean \pm SD: 2.48 \pm 0.86 ), while the highest residents' dissatisfaction (i.e., least satisfaction) was about "library service" (Mean \pm SD: 1.74 \pm 0.73 ) and "computerized resources" (Mean \pm SD: $1.83 \pm 0.8)$. Regarding the "organization" component, "well-known lecture starting time" and "notification for changes" were the aspects that received the highest satisfaction (Mean \pm SD: $2.99 \pm 0.98$ and 2.98 \pm 0.89 , respectively), while the highest residents' dissatisfaction (i.e., least satisfaction) was related to "having a clear idea about what is expected of residents" and "using of residents' feedback to improve the course" (Mean \pm SD: $2.25 \pm 0.85$ and $2.26 \pm 0.83$, respectively). Regarding residents' satisfaction toward the "overall satisfaction" component, "learning valuable information" was the item that received the highest appreciation (Mean \pm SD: $2.55 \pm 0.89$ ), while the highest residents' dissatisfaction (i.e., least satisfaction) was related to "the course increases residents' interest in family medicine" and "the course improves residents' skills" (Mean \pm SD: 2.20 \pm 0.97 and 2.30 \pm 0.89 , respectively).

Table (4) shows that, regarding the "presenters and presentations" component, residents' satisfaction mean percent scores regarding the "presenters and presentations" component differed significantly according to their age groups $(\mathrm{p}=0.013)$, with lowest mean percent scores among those aged $>30$ years. Similarly, their satisfaction mean percent scores differed significantly according to their academic levels $(\mathrm{p}=0.001)$, with lowest mean percent scores among those in R4. However, mean percent scores did not differ according to participants' gender, affiliation to JPFCM, presenters or time. Regarding the "environment and teaching method" component, residents' satisfaction mean percent scores differed significantly according to their age groups $(\mathrm{p}=0.017)$, with lowest mean percent scores among those aged $>30$ years. Similarly, their satisfaction mean percent scores differed significantly according to their academic levels $(\mathrm{p}=0.005)$, with lowest mean percent scores among those in R4. Residents' mean percent scores satisfaction differed significantly according to their city $(\mathrm{p}=0.007)$, with those in Makkah having the highest mean scores. Moreover, satisfaction percent scores differed significantly according to residents' affiliation to JPFCM and time ( $<<0.001$ for both), with higher mean scores among those outside the Joint Program and those with full time. However, percent scores did not differ significantly according to participants' gender or presenters. Regarding the "organization" component, residents' satisfaction percent scores differed significantly according to their age groups $(\mathrm{p}=0.008)$, with lowest mean percent scores among those aged $>30$ years. Similarly, their satisfaction mean percent scores differed significantly according to their academic levels $(p=0.005)$, with lowest mean percent scores among those in R4. Moreover, satisfaction percent scores differed significantly according to residents' affiliation to JPFCM (0.025), with higher mean scores among those outside the Joint Program. Residents' satisfaction mean percent scores differed significantly according to presenters $(\mathrm{p}=0.005)$, with residents having the highest mean score and according to participants time $(\mathrm{p}=0.014)$, with lowest scores about half day. However, mean percent scores did not differ significantly according to residents' gender or city. Regarding the "overall satisfaction" component, residents' satisfaction percent scores differed significantly according to their age groups ( $\mathrm{p}=0.030)$, with lowest mean percent scores among those aged >30 years. Similarly, their satisfaction percent scores differed significantly according to their academic levels $(\mathrm{p}=0.006)$, with lowest mean percent scores among those in $\mathrm{R} 4$. Residents' mean percent scores differed significantly according to presenters $(\mathrm{p}=0.026)$, with residents having the highest mean score and according to time $(\mathrm{p}=0.013)$, with lowest scores about half day. However, percent scores did not differ according to participants' gender, city, affiliation.

Table (1):- Characteristics of study sample.

\begin{tabular}{|c|c|c|}
\hline \multicolumn{1}{|c|}{ Characteristics } & No. & $\%$ \\
\hline Age groups (in years) & & \\
\hline$\bullet<25$ & 22 & 15.0 \\
\hline$\bullet 26-30$ & 105 & 71.4 \\
\hline$\bullet>30$ & 20 & 13.6 \\
\hline
\end{tabular}




\begin{tabular}{|c|c|c|}
\hline Gender & & \\
\hline$\bullet$ Male & 45 & 30.6 \\
\hline$\bullet$ Female & 102 & 69.4 \\
\hline Level & & 27.9 \\
\hline$\bullet \quad$ R1 & 41 & 25.2 \\
\hline$\bullet$ R3 & 37 & 25.2 \\
\hline$\bullet \quad$ R4 & 37 & 21.8 \\
\hline City $\quad 32$ & 38.8 \\
\hline$\bullet \quad$ Jeddah & & 28.6 \\
\hline$\bullet \quad$ Makkah & 57 & 32.7 \\
\hline$\bullet \quad$ Al-Taif & 42 & \\
\hline Resident's affiliation to JPFCM & 48 & 93.9 \\
\hline$\bullet \quad$ Affiliated & 138 & 6.1 \\
\hline$\bullet \quad$ Not affiliated & 9 & 97.3 \\
\hline Presenters & & 2.7 \\
\hline$\bullet \quad$ Residents & 143 & \\
\hline$\bullet \quad$ Seniors & 4 & 93.9 \\
\hline Time $\quad$ Half day & 138 & 6.1 \\
\hline$\bullet \quad$ Full day & 9 & \\
\hline
\end{tabular}

Table (2):- Residents' percent scores (Mean $\pm \mathrm{SD}$ ) for the four components of satisfaction toward half day release course.

\begin{tabular}{|l|c|}
\hline \multicolumn{1}{|c|}{ Components } & Mean \pm SD \\
\hline Presenter and Presentation & $53.3 \pm 14.8$ \\
\hline Environment and Teaching Methods & $65.5 \pm 14.3$ \\
\hline Organization & $63.2 \pm 16.4$ \\
\hline Overall satisfaction & $59.2 \pm 19.8$ \\
\hline
\end{tabular}

Table (3):- Residents' satisfaction scores (Mean \pm SD) for items of satisfaction components.

\begin{tabular}{|c|c|c|}
\hline \multicolumn{1}{|c|}{ Items of Satisfaction } & Mean & SD \\
\hline Presenters and presentation: & & 0.71 \\
\hline$\bullet \quad$ Enthusiasm & 2.46 & 0.69 \\
\hline$\bullet \quad$ Interaction with audience & 2.58 & 0.78 \\
\hline$\bullet \quad$ Topic preparation & 2.74 & 0.71 \\
\hline$\bullet \quad$ Skills & 2.49 & 0.92 \\
\hline$\bullet \quad$ Topic relevance & 2.62 & 0.79 \\
\hline$\bullet \quad$ Practical topic & 2.70 & 1.00 \\
\hline Environment and teaching methods: & 2.72 & \\
\hline$\bullet \quad$ Suitable class & & 0.92 \\
\hline$\bullet \quad$ Use of audiovisual aids & 2.41 & 0.86 \\
\hline$\bullet \quad$ Balanced presentation & 2.48 & 0.82 \\
\hline$\bullet \quad$ Learning resources & 2.06 & 0.85 \\
\hline$\bullet \quad$ Library service & 2.26 & 0.73 \\
\hline Computerized resources & 1.74 & 0.80 \\
\hline Organization: & 1.83 & \\
\hline$\bullet \quad$ Ran smoothly & & 0.85 \\
\hline$\bullet \quad$ Organized lecture table & 2.32 & 0.90 \\
\hline$\bullet \quad$ Notification for change & 2.47 & 0.89 \\
\hline$\bullet \quad$ Well known start time & 2.98 & 0.98 \\
\hline
\end{tabular}




\begin{tabular}{|c|c|c|}
\hline$\bullet \quad$ Supervisor motivation & 2.48 & 0.96 \\
\hline$\bullet$ supervisor feedback & 2.41 & 0.87 \\
\hline$\bullet \quad$ Residents' feedback to improve the course & 2.26 & 0.83 \\
\hline$\bullet \quad$ Clear idea about what is expected & 2.25 & 0.85 \\
\hline Overall satisfaction: & & \\
\hline$\bullet \quad$ The course improves residents' skills & 2.30 & 0.89 \\
\hline$\bullet \quad$ The course tries to get the best out of its residents & 2.32 & 0.93 \\
\hline$\bullet \quad$ Developing residents to be creative & 2.34 & 0.91 \\
\hline$\bullet \quad$ Providing opportunities to discuss important topics & 2.46 & 0.89 \\
\hline$\bullet \quad$ Learning valuable information & 2.55 & 0.89 \\
\hline$\bullet \quad$ Increasing residents' interest in family medicine & 2.20 & 0.97 \\
\hline$\bullet \quad$ Overall assessment of HDRC & 2.30 & 0.86 \\
\hline
\end{tabular}

Table (4):- Residents' satisfaction percent scores (Mean $\pm \mathrm{SD}$ ) according to their characteristics.

\begin{tabular}{|c|c|c|c|c|c|}
\hline Characteristics & No. & $\begin{array}{c}\text { Presenter } \\
\text { and Presentation }\end{array}$ & $\begin{array}{l}\text { Environment and } \\
\text { teaching methods }\end{array}$ & Organization & $\begin{array}{c}\text { Overall } \\
\text { Satisfaction }\end{array}$ \\
\hline \multicolumn{6}{|l|}{ Age groups } \\
\hline - $\quad<25$ & 22 & $67.2 \pm 9.5$ & $50.8 \pm 12.4$ & $66.3 \pm 12.0$ & $61.4 \pm 17.7$ \\
\hline - $26-30$ & 105 & $66.8 \pm 13.9$ & $55.3 \pm 14.7$ & $64.5 \pm 16.0$ & $60.8 \pm 19.8$ \\
\hline - $>30$ & 20 & $56.8 \pm 18.2$ & $45.6 \pm 15.3$ & $52.8 \pm 19.3$ & $48.3 \pm 19.3$ \\
\hline P-value & & $0.013^{*}$ & $0.017^{*}$ & $0.008^{*}$ & $0.030^{*}$ \\
\hline \multicolumn{6}{|l|}{ Gender } \\
\hline - Male & 45 & $65.3 \pm 15.2$ & $53.7 \pm 14.8$ & $65.7 \pm 15.7$ & $61.8 \pm 19.7$ \\
\hline - $\quad$ Female & 102 & $65.5 \pm 14.0$ & $53.1 \pm 14.8$ & $62.0 \pm 16.7$ & $58.0 \pm 19.8$ \\
\hline P-value & & 0.929 & 0.834 & 0.215 & 0.296 \\
\hline \multicolumn{6}{|l|}{ Level } \\
\hline - $\quad \mathrm{R} 1$ & 41 & $69.1 \pm 15.2$ & $54.7 \pm 13.4$ & $63.7 \pm 20.1$ & $59.6 \pm 23.6$ \\
\hline - $\quad \mathrm{R} 2$ & 37 & $69.0 \pm 10.9$ & $58.1 \pm 14.8$ & $69.0 \pm 14.2$ & $66.6 \pm 16.3$ \\
\hline - $\quad \mathrm{R} 3$ & 37 & $65.5 \pm 12.5$ & $53.5 \pm 14.2$ & $63.6 \pm 13.6$ & $59.5 \pm 18.1$ \\
\hline - $\quad \mathrm{R} 4$ & 32 & $56.7 \pm 15.5$ & $45.8 \pm 14.8$ & $55.2 \pm 14.0$ & $49.9 \pm 16.9$ \\
\hline $\mathrm{P}$-value & & $0.001 *$ & $0.005^{*}$ & $0.005^{*}$ & $0.006^{*}$ \\
\hline \multicolumn{6}{|l|}{ City } \\
\hline - Jeddah & 57 & $65.8 \pm 14.6$ & $50.4 \pm 15.9$ & $60.6 \pm 18.0$ & $55.9 \pm 21.7$ \\
\hline - Makkah & 42 & $67.4 \pm 14.5$ & $59.3 \pm 13.8$ & $63.6 \pm 15.0$ & $62.1 \pm 16.9$ \\
\hline - $\quad$ Al-Taif & 48 & $63.4 \pm 13.9$ & $51.5 \pm 12.9$ & $65.8 \pm 15.5$ & $60.5 \pm 19.6$ \\
\hline $\mathrm{P}$-value & & 0.405 & $0.007 *$ & 0.261 & 0.264 \\
\hline \multicolumn{6}{|l|}{ Affiliation to JPFCM } \\
\hline - $\quad$ Affiliated & 138 & $65.0 \pm 14.3$ & $52.1 \pm 24.3$ & $62.4 \pm 16.4$ & $58.4 \pm 19.5$ \\
\hline - $\quad$ Not affiliated & 9 & $72.2 \pm 13.2$ & $72.7 \pm 7.3$ & $75.0 \pm 11.7$ & $71.3 \pm 21.5$ \\
\hline P-value & & 0.146 & $<0.001 *$ & $0.025^{*}$ & 0.058 \\
\hline \multicolumn{6}{|l|}{ Presenters } \\
\hline - Residents & 143 & $65.8 \pm 13.9$ & $53.6 \pm 14.7$ & $63.8 \pm 15.9$ & $59.8 \pm 19.4$ \\
\hline - $\quad$ Seniors & 4 & $54.5 \pm 26.8$ & $43.8 \pm 16.1$ & $40.6 \pm 21.5$ & $37.5 \pm 25.0$ \\
\hline P-value & & 0.120 & 0.191 & $0.005^{*}$ & $0.026^{*}$ \\
\hline \multicolumn{6}{|l|}{ Time } \\
\hline - Half day & 139 & $65.0 \pm 14.3$ & $52.2 \pm 14.3$ & $62.4 \pm 16.4$ & $58.2 \pm 19.5$ \\
\hline - $\quad$ Full day & 8 & $74.6 \pm 12.0$ & $72.9 \pm 7.7$ & $77.0 \pm 10.8$ & $76.0 \pm 17.2$ \\
\hline P-value & & 0.065 & $<0.001 *$ & $0.014^{*}$ & $0.013^{*}$ \\
\hline
\end{tabular}

* Statistically significant $(p<0.05)$ 


\section{Discusson:-}

The establishment of meaningful learning opportunities during residency programs is essential for the safe and effective provision of patient care. Family medicine residency programs constitute one of the medical education's most important interfaces with public, social, and health care policy development. Family medicine training programs establish how family physicians will be available in the future. They also determine, through the type and location of the residency positions, where those residents will practice after graduation ${ }^{2}$.

The academic half-day is an alternative to the noon conference curriculum and involves a dedicated, weekly, threeto four-hour teaching period that can replace the daily one-hour sessions. The literature on the effectiveness of the half-day release course is very scarce, and there is not a single study to assess residents' satisfaction toward any half day courses in Family Medicine. ${ }^{3}$

Therefore, the present study aimed to assess resident's satisfaction about their Half Day Release Course of the family medicine program in Makkah Al-Mukaramah Region and identify determinants of their dissatisfaction about their Half Day Release Course.

The academic half-day model also increased resident satisfaction, similar to findings from a study of the implementation of an academic half-day curriculum in an orthopedic residency program.

Ha et al. ${ }^{4}$ reported that academic half-day curriculum was associated with a better performance compared with a noon conference curriculum. In addition, residents in the academic half-day reported higher conference attendance and overall satisfaction.

Findings of the present study showed that, among the four components of residents' satisfaction toward half day release course, "environment and teaching methods" had the highest mean percent satisfaction score, while "presenter and presentation" had the least mean percent satisfaction score.

The present study showed that the highest residents' dissatisfaction toward presenters and presentations aspects were related to "presenter enthusiasm" and "interaction with the audience."

On the other hand, the highest resident's dissatisfaction toward environment and teaching methods aspects were toward "accessibility of library service" and "availability of computerized resources." Besides, the maximum dissatisfaction toward organization issues was related to "using of residents' feedback to improve the course" and "if the residents have a clear idea of what is expected of them in this course." Also, the highest residents" dissatisfaction toward satisfaction aspects was related to "if the course increase residents" interest toward family medicine" and "if the course tries to get the best out of its residents."

These findings are in agreement with those of Ramanayake et al. ${ }^{5}$, in Sri Lanka, who found that that the vast majority $(92 \%)$ of family medicine candidates appreciated its environment and teaching methods.

Swanson et al. ${ }^{6}$ stressed the importance of presenter and presentation for residents' learning. They noted that instruction received by residents from other residents, especially through presentations, informal discussion and interaction forms an important part of their postgraduate education. The important role of residents as teachers is beginning to be recognized. Teaching, which includes the ability to present, is generally regarded as in important function of the resident.

Results of the present study showed that participants' satisfaction toward all four components of satisfaction (i.e., presenter and presentation, environment and teaching methods, organization, and satisfaction) differed significantly according to residents' age groups and academic levels. The lowest mean percent scores (i.e., highest dissatisfaction) among those aged >30 years and those in R4. In only two components of satisfaction (i.e., organization and satisfaction), female residents were slightly more dissatisfied than males. However, there were no statistically significant differences regarding all components of satisfaction according to residents' gender.

These findings are in agreement with those of AlShareef ${ }^{7}$, in Jeddah City, Saudi Arabia, who noted that Family Medicine residents' dissatisfaction is highest among R4 residents since R4 is the final year and residents must finish 
it with a lot of heavy works during it to pass the board exams. She also reported no statistically significant differences in residents' dissatisfaction according to their gender.

Moreover, participants' satisfaction also differed significantly according to their lecture setting, being highest higher regarding lectures outside the Joint Program.

This finding of least dissatisfaction among residents outside the Joint Program mainly the National Guard may be explained by the fact that National Guard residents have full day release course instead of half day.

Differences in satisfaction according to different sectors has been explained by Al-Khaldi et al. ${ }^{8}$, who stated that, in Saudi Arabia, postgraduate training in Family Medicine is conducted in 6 different health sectors, i.e., Ministry of Health, Ministry of Defense, Ministry of National Guard, Ministry of Interior, Ministry of Higher Education and the private sector. Each one of these sectors has its different agenda, priorities, policies and procedures. Some sectors have good infrastructures, and others have well-established curative and preventive programs, whereas some other sectors may have a good number of qualified trainers.

Participants' dissatisfaction regarding environment and teaching method, organization and satisfaction differed significantly according to presenters, with seniors (consultant or specialist) having the highest dissatisfaction. Moreover, participants expressed higher dissatisfaction toward the half day course.

Chalk ${ }^{9}$, in Canada, emphasized that the half day release academic course has been the object of both skepticism and criticism. Nevertheless, they concluded that the academic half-day has become the norm, it has occupied a considerable portion of the total hours in the family medicine residency. Whether it is educationally sound, whether its impact on residency training is favorable, bad, or even a mixed blessing, or how the academic half-day affects residents' professional development, are few examples of the questions that are usually asked, and which certainly deserve further exploration.

In conclusion, the highest satisfaction among FM residents' regarding HDRC is related to the "environment and teaching methods" component, while their greatest dissatisfaction is related to the "presenter and presentation" component. The highest dissatisfaction toward half day release course are among residents aged $>30$ years and those at R4. Residents' dissatisfaction differ significantly according to their study setting, being least (i.e., highest satisfaction) for all components toward lectures outside the Joint Program. Residents' dissatisfaction regarding the environment and teaching method, organization and satisfaction differ significantly according to presenters, with seniors (consultant or specialist) having the highest dissatisfaction. Residents have more dissatisfaction toward the half-day course than the full-day course.

Therefore, it is the HDRC for FM residents needs to be improved, especially for those at R4 to minimize their dissatisfaction toward it. Further studies are needed to identify the main reasons for FM residents' dissatisfaction toward their HDRC across all programs in Saudi Arabia.

\section{References:-}

1. American Academy of Family Physicians. AAFP Policies on health issues. Family Practice 2003.

2. Abdulrahman KA Bin, Al-dakheel A. Family Medicine Residency Program in Kingdom of Saudi Arabia: Residents Opinion. 2006;22(3).

3. Batalden MK, Warm EJ, Logio LS. Beyond a curricular design of convenience: replacing the noon conference with an academic half day in three internal medicine residency programs. Acad Med. 2013;88(5):644-651.

4. Ha D, Faulx M, Isada C, Kattan M, Yu C, Olender J, Nielsen C, Brateanu A. Transitioning from a Noon Conference to an Academic Half-Day Curriculum Model: Effect on Medical Knowledge Acquisition and Learning Satisfaction. Journal of Graduate Medical Education 2014; 93-99.

5. Ramanayake RPJC, De Silva AHW, Perera DP, Sumanasekara RDN, Gunasekara R, Chandrasiri P. Evaluation of Teaching and Learning in Family Medicine by Students: A Sri Lankan Experience. J Family Med Prim Care 2015; 4(1): 3-8.

6. Swanson RW, Spooner HJ, Reeder BA, Haight KR, Senthilselvan A. Improving presentation skills of family medicine residents: a randomized controlled study. Medical Education 1992; 26: 241-247.

7. AlShareef M. Satisfaction of family physicians during their training program, Jeddah, Saudi Arabia. Int J Med Sci Public Heal [Internet]. 2014;3(4):4. Available from: http://www.scopemed.org/?mno=156495 
8. Al-Khaldi Y, Al-Meqbel T, Al-Shmmari S, Al-Yahya O, AlBar A, AlDawood K, et al. Challenges facing postgraduate training in family medicine in Saudi Arabia: Patterns and solutions. J Heal Spec 2014;2(2):61.

9. Chalk C. The Academic Half-Day in Canadian Neurology Residency Programs. Can. J. Neurol. Sci. 2004; 31: 511513. 